\title{
Managing Innovation: A Multidisciplinary Scenario Development Approach
}

\author{
Esmond Urwin and Michael Henshaw \\ Systems Engineering Innovation Centre, Holywell Park, Loughborough University, \\ Loughborough, Leicestershire, LE11 3TU, United Kingdom \\ \{e.n.urwin,m.j.d.henshaw\} alboro.ac.uk
}

\begin{abstract}
The UK Ministry of Defence (MoD) is focusing on and shifting toward a Network Enabled Capability (NEC) approach for improved military effect. This is being realised through the physical networking and coherent integration of existing and future resources including sensors, effectors, support services, and decision makers. This paper is a case study (for NEC) of how the development and use of scenarios for demonstrating academic research can aid and help manage innovation. It illustrates the development, use and application of a multiple stakeholder scenario within the NECTISE research programme that helped establish and exploit a collaborative multidisciplinary working environment and how it helped manage innovative academic research. Our experience suggests that this approach can support the engagement of multiple stakeholders with differing perceptions and priorities and will provide a scenario development strategy for improved research and innovation for many other large systems.
\end{abstract}

Keywords: Scenario Development, Innovation Management, Scenario Based Planning, Collaborative Working, Multidisciplinary Stakeholder Management.

\section{Introduction}

In today's commercial and economic environment, only highly innovative organisations will remain competitive. Although it is an easily recognised quality of an organisation, innovation is hard to quantify, articulate and measure. What works for one organisation or situation might not work for another. Much has been written about innovation, its problems and how to approach and tackle these [1]. One of the main factors though seems to be the ability to cope with, and manage, risk. A recent trend is to apply a systems thinking approach to view internal and external influencing factors and help manage innovation [2]. Although some organisations have prescribed innovation methods, inovation is as much about a social process and context as it is a systematic process, thus making it somewhat naturalistic in character $[3,4]$. How does one manage innovation? With numerous interactions between numerous different stakeholders complexity must surely arise and thus it must concern the ability of people to control such factors [5]. 
Scenario planning is one way to help encourage, plan for and manage innovation. This technique is heavily used for military planning and by the petrochemical industry [6]. Scenarios allow information and knowledge to be modelled and represented for a given context. Doughety et al. [7] cite the need for innovative sense making, whereby knowledge of technology and the contexts in which they can be applied are combined to assess and consider possibilities and bring about more successful innovation. Scenarios are an excellent method for enabling this point of view, bringing together disparate sources of information and knowledge that may not be available or on hand to organisations in day-to-day activities. Such an approach allows organisations to accumulate knowledge, transfer that knowledge, explore their environment and consider multiple alternatives as possible routes in which to innovate $[8,9,10]$. Worthington et al. [11] positively argue for scenario planning to enhance innovation.

Network Enabled Capability (NEC) is the UK Ministry of Defence's (MoD) endeavour to enhance [military] capability through the networking of existing and future military assets in order to respond to the rapidly changing conflict environment in which its forces must operate [12,13]. Capability is a key concept and is defined as the enduring ability to generate a desired operational outcome or effect, and is relative to the threat, physical environment and the contributions of joint or coalition forces [14]. At the highest level, capability is described as the seven elements of command, inform, prepare, project, protect, sustain, and operate. These are constructed through planned capabilities such as counter airborne threat, etc. NEC requires the integration of independent components, systems, and networks that can evolve and operate in a collaborative and dependable manner, and manage system and component changes. It makes demands on the overall delivered system that cannot be fulfilled by traditional system engineering design principles addressing independent closed-world systems $[15,16]$. NEC is realised through services that form networks of systems of systems that are dynamic, large-scale and subject to continual change and evolution.

This paper describes our experience of developing a scenario for the demonstration of innovative research that addressed the NEC challenge and how such a scenario development process helped to stimulate and manage innovation. Section 2 describes the development of the scenario, the approach, and factors taken into consideration and how such a process managed innovation. Section 3 sets out the developed scenario and section 4 discusses aspects of the approach, draws conclusions and outlines future work.

\section{Scenario Development}

NECTISE (Network Enabled Capability Through Innovative Systems Engineering) was an integrated research programme in systems engineering that addressed a number of the challenges posed by a networked, capability-based acquisition environment. The programme comprised four topic groups: Through-Life System Management (TLSM), Decision Support, Systems Architectures, and Control and Monitoring. TLSM investigated how the desired capability and the contributory systems should be developed, sustained and evolved. This included aspects such as the adaptable operational effectiveness as well as affordability, safety, qualification and achievability of proposed system elements. The decision support topic group developed an Integrated 
Decision Support Environment to support through-life management by enterprises engaged in capability-based acquisition. The Architectures topic group investigated methods of evaluation of systems architectures based on quality of service metrics. The Control and Monitoring group investigated health management, prognostics and reconfiguration of co-operating autonomous systems operating in a NEC environment. The programme was jointly funded by the Engineering and Physical Sciences Research Council and BAE Systems, and included ten UK universities who worked closely with industrial engineers.

Innovation comprises not only the inventiveness that might be termed the 'idea', but also the understanding of how the idea will be used in practice, the selection of those good ideas and the determination to realise the ideas as a benefit (commercial or otherwise), i.e. successfully implement those ideas [1]. Berkum [17] has argued that the eureka moment, which suggests the sudden emergence of an idea is, in reality, often the moment that a number of pieces of the jigsaw come together into the realisation of how an idea might work. In the sections that follow, we shall show how the use of a scenario allows team members to see the larger picture and thus identify the interactions between contributing ideas and systems, leading to integrated solutions; i.e. scenarios help individuals and teams see the whole of the jigsaw. Furthermore, the exhibiting of individual research elements within a realistic context enables stakeholders to understand more clearly how the research may be exploited and, thus, enable the planning of research exploitation across an academic-industry team.

The primary purpose of the NECTISE Scenario was the demonstration and showcasing of the research developed within the programme, in order to promote the research to a range of programme stakeholders. The aim of the series of demonstrations was to show the nature of the research within a meaningful context such that new concepts and ideas could be clearly understood by stakeholders and their views solicited and structured to maximize the opportunities for exploitation. Creating a successful demonstration event that exhibited the research across the NECTISE programme required the development of a scenario that captured the eclectic interests of the stakeholders. Carroll [18] states that scenarios can provide sufficient data, information and context to paint a picture that is wholly believable and real enough to be considered viable for experimentation and analysis. Use of a scenario provides a realistic context through which an audience can engage with and understand the research, explore its benefits and how it can potentially provide value and future advancement for their business. The aim was to create a scenario that satisfied a number of key criteria:

- Include multiple stakeholders' requirements and multiple timeframes.

- Be representative of NEC and its implications for battlespace, the defence industry, UK MoD and the research activities in the programme

- Be sufficiently straight forward to be easily understood by non-experts, but at the same time sufficiently rich to be informative to domain experts.

- Enable the demonstration of multi-disciplinary research outputs.

NECTISE had a range of stakeholders with varied interests. BAE Systems had a number of business streams in the land, air, sea and communications domains engaged with the project. The UK Engineering and Physical Sciences Research Council was a stakeholder with the objective of funding and disseminating good quality and 
industrially relevant research. In addition, there was the UK MoD, other commercial organisations in the defence supply chain, and academics and industries with interests in improving systems engineering. This wide range of stakeholders naturally results in multiple points of view that had to be accommodated within the demonstration scenario in order to show how the research could be of benefit to all.

When demonstration planning began, there were no public domain scenarios available for NEC, and the team was forced to develop one. Two scenario building tools were used to ensure a disciplined and relevant scenario was developed. The first was The Technical Cooperation (TTCP) Program Guide for Understanding and Implementing Defense Experimentation (GUIDEx) [19] which set out the documentation that would help create a scenario for defence experimentation and enable rigour and structure to be designed into it. The second was the Whitworth et al. framework [20] for creating scenarios, which stipulates a number of essential information classes that can be used to elicit, structure and organise the information to enable a coherent approach to scenario writing.

The technical goals, aims and objectives for the scenario were set by the prioritised NECTISE project requirements, thus these were the starting point. A range of factors and techniques were then used to develop the scenario such as goal setting, market forces, stakeholder needs and wants, success criteria and impact analysis [21,22]. From these a set of military scenario examples was created through which researchers could examine their own work. This allowed them to imagine and create potential future states against which to relate their work and to showcase it. Domain experts were invited to regularly assess progress and the content of the scenario.

When the scenario had reached an initial level of maturity, a formal two-day scenario workshop was held with all of the NECTISE researchers and academics, along with invited experts from academia and industry, and representatives from the MoD (military and civilian). The outputs from the workshop established the context of the scenario, four main timeframes, the main concepts and storylines; it allowed all of these to be validated and grounded in reality by domain experts from industry and the UK MoD.

Major design reviews were held at two critical points with the industry partner to assess the approach and planning for the demonstrations. Part of this was to assess the viability of the scenario which considered the use of requirements from all of the stakeholders involved and whether they were fully represented. This helped formalise the scenario and the processes used to create it and ensured that each stakeholder's perspectives and requirements were modelled to explicitly represent all of the inputs to the scenario and act as a completeness check. With this in mind the final assessment involved a NEC expert from the MoD to assess and verify the scenario.

Over a period of time, the regular stakeholder workshops followed the process of innovation, i.e. idea generation, idea selection and idea implementation [1]. The workshops allowed the generation of new ideas and concepts to flourish. Through an extensive process of debate and deliberation the most important ideas were selected by consensus. These determined the constitution of the scenario and how it should be represented (i.e. the 'what' and the 'how'). This not only helped the development of the scenario but also the individual research groups involved. The context and knowledge that had been used to create the scenario was therefore helping the innovative research within NECTISE (both for academia and industry) to focus upon the key 
customer issues, understand the context within which the research was being carried out and internally relate the components of the NECTISE programme.

The scenario was developed using sound factual evidence, realistic future trends and actual customer and stakeholder needs. It assembled a considerable body of knowledge that would have been difficult to assemble by any other means. Ideas and concepts were continually assessed and validated by domain experts, which created a plausible scenario. Moreover this approach allowed researchers access to industrial knowledge applied to their research and to have it validated and assessed by the multiple stakeholders. The scenario is a unique reference point for NEC research for academics, the MoD and defence industry within the UK.

Figure 1 illustrates the multidisciplinary scenario development approach taken and the benefits that can be gained from it. The process allows academia to establish a context for their research; this enables better understanding of the factors involved, timescales and what is needed by industry from the subject area under review. This allows exploration of the potential possibilities looking at current and future business approaches when conducting impact analysis of external perturbations and internal industrial changes. Performing these de-risks the exploitation potential of the research and allows industry to better understand the research and its applications.

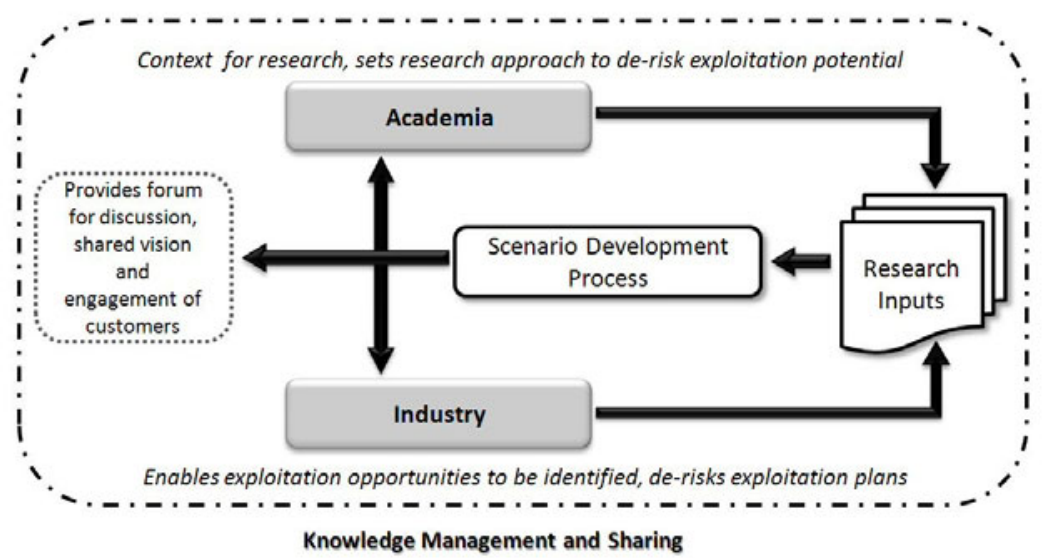

Fig. 1. Scenario Development benefits for academia and industry

Industry can benefit from using a scenario development approach, by highlighting and identifying exploitation opportunities for products, processes and future strategies. Engaging with academic research and participating in such a collaborative development process will enable a more thorough and wider ranging exploration of the factors involved, potential approaches to take and show how business can adapt and evolve to meet market conditions and derive benefit, thus de-risking exploitation plans. The whole development process can act as a knowledge gathering, management and sharing activity allowing different communities to engage with each other, share experiences and provide a forum for discussion. 
The scenario development process generated a number of innovative ideas from the programme which were brought about by mixing the research teams during the workshops. An agility framework for systems engineering was developed [23] that can identify processes, tools and techniques to build agility into systems development process. Additionally a number of agile methodologies were developed for service orientated architectures to adapt to changes that can occur in the process of service development, discovery and integration [24]. To complement both of these and other approaches a capability framework for NEC readiness was created, that mapped and formalised relationships between civilian and military domains [15].

\section{NECTISE Scenario}

The NECTISE scenario needed to provide an exemplar context for research outputs that might be applied to the immediate (short timeframe) situation of a military operation, right up to systems engineering that would be applicable at the long-term capability planning level. The scenario was built up from four vignettes each representing a different period in the capability process, the range of influence of decisions, and different groups of stakeholders.

The basis of the NECTISE scenario is that of a foreign state threatening international airspace with a surface-to-air missile (SAM) weapon system. The operational mission is to neutralise the SAM site to reduce the threat issued against civil air activity. It is composed of four vignettes, each representing a particular stage of capability development and/or use for NEC, and each representing different timeframes. The main question concerns the development of military capability from inception and planning at the government level, development and assessment within the industryMoD enterprise, through to use by military forces in the battle space. It looks at an incremental increase in surveillance system capability for monitoring no-fly zones.

- Vignette 4 represents capability planning. At this level, the decisions are taken by the MoD with industry having a supporting role. Systems engineering approaches are studied by which industry can support the MoD's capability planning framework. Typically the timeframe for this level is measured in years.

- Vignette 3 is the capability development stage where decisions are made about capability change including the development of options, selection, and change plans. This is applicable to industry and the MoD. Typically the timeframe for this is from years to months.

- Vignette 2 looks at the deployment of new, changed, or updated capability. Again, this is applicable to both industry and the MoD. The timeframe for this vignette is measured in months to weeks.

- Vignette 1 is concerned with a military operation that is NEC-relevant. This showed how technologies and systems approaches can provide agility benefits at this level; this is also applicable to industry and MoD. The timeframe here is hours and minutes.

The purpose was not to show a consolidated solution to the scenario, but rather to show the focused NECTISE contributions to the overall landscape. The scenario was to set a viable and realistic context in which to view the research outputs and as such did not seek to assert that the described possible future state is more or less likely than another. 


\section{Discussion and Conclusion}

The creation and development of a well formed and plausible scenario is an extremely time consuming and iterative process. Nevertheless, scenarios provide a useful method for conveying ideas and concepts, and also as a platform for exploring potential futures at the evaluation stage of the development process.

For the process of developing scenarios it was highly beneficial to make stakeholders aware of each other's requirements, needs and wants and to properly represent those requirements. By way of regular collaborative workshops the process of people relating their own needs and perspectives against others not only allowed them to better understand the context of the research and assess other stakeholders' perspectives, but also forced them to evaluate their own perspectives and to understand more fully the integration of research elements. This fostered a collaborative environment with which an improved understanding was obtained by industry and academia to develop ideas, and select them in an open and frank manner, helping to develop a realistic scenario and manage innovative academic research.

The NECTISE scenario described herein was used to successfully demonstrate research to audiences around the UK. People engaged easily with the scenario storyline, were able to understand the concepts and ultimately appreciate the benefit of the contextualised research.

This paper portrays the process of scenario development, the factors involved and the resultant scenario. Such an approach can provide benefits to research programmes both for academia and industry, and can be applied in a number of different contexts and areas. The main factor to highlight is that it was the process of development and not the scenario itself that helped to stimulate and manage innovation.

Potential future work is to expand the number and types of processes within each of the vignettes and make them more applicable to different contexts and industries. But in the first instance it would be desirable to better define the stages, populate them with different sets of information and data to develop metrics for the entire scenario so as to improve the potential for analysis and performance measurement.

\section{References}

1. Bessant, J., Tidd, J.: Innovation and Entrepreneurship. Wiley, Chichester (2007)

2. O'Connor, G.C., Ravichandran, T., Robeson, D.: Risk Management Through Learning: Management Practices for Radical Innovation Success. Journal of High Technology Management Research 19, 70-82 (2008)

3. Adamides, E.D., Karacapilidis, D.: Information technology support for the knowledge and social processes of innovation management. Technovation 26, 50-59 (2006)

4. Roberts, R.: Managing Innovation: the Pursuit of Competitive Advantage and the Design of Innovation in Intense Environments. Research Policy 27, 159-175 (1998)

5. Sneep, C.: Innovation Management in a Theoretical Perspective. In: Geschka, H., Hubner, H. (eds.) Innovations Strategies. Elsevier Science Publishers BV, Amsterdam (1991)

6. Royal Dutch Shell plc, http: / /www. shell.com/

7. Dougherty, D., Borrelli, L., Munir, K., O’Sullivan, A.: Systems of Organizational Sensemaking for Sustained Product Innovation. Journal of Engineering Technology Management 17, 321-355 (2000) 
8. Gersick, C.J.G.: Revolutionary Change Theories: A Multilevel Exploration of the Punctuated Equilibrium Paradigm. Academy of Management Review 16, 274-309 (1991)

9. Kuhlman, S.: Future Governance of Innovation Policy in Europe: Three Scenarios. Research Policy 70, 953-976 (2001)

10. Kuhlman, S., Edler, J.: Scenarios of Technology and Innovation Policies in Europe: Investigating Future Governance. Technological Forecasting \& Social Change 70, 619-637 (2003)

11. Worthington, W.J., Collins, J.D., Hitt, M.A.: Beyond Risks Mitigation: Enhancing Corporate Innovation with Scenario Planning. Business Horizons (2009) (article in Press)

12. UK Ministry of Defence, Network Enabled Capability, Ministry of Defence (2005)

13. UK Ministry of Defence, Understanding Network Enabled Capability, Ministry of Defence (2009)

14. UK, Ministry of Defence, Capability Management Handbook, Ministry of Defence (2007)

15. Neaga, E.I., Henshaw, M.J.D., Yue, Y.: The Influence of the Concept of Capability-based Management on the Development of the Systems Engineering Discipline. In: The Proceedings of the 7th Annual Conference on Systems Engineering Research. Loughborough University, UK (2009)

16. Russell, D., Looker, N., Liu, L., Xu, J.: Service- Oriented Integration of Systems for Military Capability. In: The 11th IEEE International Symposium on Object/component/service-oriented Real-time Distributed Computing, Orlando, USA, p. 33 (2008)

17. Berkun, S.: The Myths of Innovation. O'Reilly Media, Sebastopol (2007)

18. Carroll, J.M.: Five Reasons for Scenario Based Design. Interacting with Computers 13, 43-60 (2000)

19. Guide for Understanding and Implementing Defense Experimentation (GUIDEx): The Technical Cooperation Program (2006)

20. Whitworth, I.R., Smith, S.J., Hone, G.N., McLeod, I.: How do we know that a scenario is 'appropriate'. In: 11th International Command and Control Technology Symposium, Cambridge, UK, September 26-28 (2006)

21. Tuominen, M., Petteri, P., Ichimura, T., Matsumoto, Y.: An Analysis of Innovation Management Systems' Characteristics. International Journal of Production Economics 60-61, 135-143 (1999)

22. Berkhout, F., Hertin, J., Jordan, A.: Socio-economic futures in climate change impact assessment: using scenarios as 'learning machines'. Global Environmental Change 12(2), 83-95 (2002)

23. Mackley, T., Barker, S., John, P.: Concepts of Agility in Network Enabled Capability. In: Conference on Networked Enabled Capability, Leeds, UK (2008)

24. Liu, L., Russell, D., Xu, J., Davies, J.K., Irvin, K.: Agile Properties of Service Orientated Architectures for Network Enabled Capability. In: Conference on Networked Enabled Capability, Leeds, UK (2008) 